\title{
O JOGO DE ESPELHOS DE LIMA BARRETO
}

\author{
André M. Penna-Firme ${ }^{1}$
}

\begin{abstract}
Resumo
O realismo da literatura de Lima Barreto impôs algumas questões centrais ao cenário artístico da virada para o século XX. No contexto da literatura parnasiana em seu ápice, a ficção barretiana não só buscava se aproximar da experiência concreta da vida na capital, como o fez sob um olhar invertido, caricaturizando a cidade "oficial" através de seu outro. Pensar tal literatura sob a perspectiva da virada do regime estético das artes, como descreve J. Rancière, permite entender a forma como ela toca e constrói a realidade que a envolve, e esclarece os embates que teve que travar para achar seu lugar enquanto experiência sensível. Mais do que uma mudança apenas do fazer artístico, a ficção barretiana nos indica uma reorganização da partilha do sensível dentro da sociedade carioca.
\end{abstract}

\section{Palavras-chave}

Lima Barreto; Jacques Rancière; Tragicidade; Partilha do Sensível; Contemporâneo

A virada do século XIX para o XX trouxe mudanças profundas e marcantes para a sempre agitada sociedade carioca: suas instituições modificavam-se, sua população moviase, suas classes remodelavam-se, suas ruas reformavam-se. Tudo parecia em movimento, em queda, em transformação. O paradigma das mudanças que visavam o progresso fazia mover-se tanto as estruturas burocráticas do estado, quanto a própria demografia e cartografia da cidade. Com o fim da escravidão, também populações novas desaguavam no Rio de Janeiro, desamparadas pelo Estado e procurando novas perspectivas de sobrevivência e associação. Sua presença cada vez mais constante e a mudança do estatuto social de suas cores fazia rever a própria imagem que a cidade fazia de si. Ao mesmo tempo, a nova burguesia prosperava e tomava ares e pretensões parisienses.

O progresso da cidade vai tomando forma como um duplo movimento. De um lado, a cidade oficial, vitrine e representação da cidade, com seus bondes elétricos, bailes de gala, sua nova burguesia e suas reformas, busca cada vez mais lugar dentro das grandes capitais do mundo civilizado. Ao se comparar com Buenos Aires, a população dirigente do Rio de Janeiro vê como inadiáveis as reformas de saneamento e urbanismo que possam limpar a cidade, fazer seu ar circular, abrir espaços de convivência e de passeio. O slogan "O Rio civiliza-se" se ergue como imperativo, como canto de marcha de uma civilização que

\footnotetext{
${ }^{1}$ Bacharel em História e mestrando em Filosofia com ênfase em estética, ambos pela PUC-Rio.
} 
acreditava deixar para trás seu passado colonial e se abrir ao mundo moderno e ao concerto das nações ditas civilizadas.

Do outro lado, o afluxo de novas populações para a então capital federal aos poucos mudava, invariavelmente, a constituição de sua população e, consequentemente, também sua real malha urbana, suas relações com o Estado e com as classes dirigentes, criando tensões e negociações do poder. A Praça Onze, nesse tempo, torna-se lugar paradigmático dessas mudanças. O afluxo da população negra vinda, em sua maioria, de um lado, da Bahia, e do outro, do Vale do Paraíba, torna o espaço, bem como nas adjacências os bairros da Saúde e da Gamboa, um centro de resistência da cultura negra e de produção artística e configuração social de todo especial.

A praça Onze foi, aos poucos, se tornando um lugar de reunião da população de trabalhadores que, naquele momento, incluía negros antes cativos vindos da Bahia para o trabalho no porto e judeus pobres do Leste europeu. Também se aninhavam por lá portugueses, espanhóis e italianos. A presença forte do elemento africano transformou a praça num lugar de resistência da cultura africana, já recheada de elementos das tradições cariocas. Os batuques tomam conta da região e animam as festas e cerimônias religiosas. $\mathrm{O}$ som do tambor dá um ruído novo à cidade e marca o passo de um novo tempo. (RODRIGUES, 2016, p. 98)

O novo século e, com ele, o otimismo do progresso que toma de assalto a nova configuração da burguesia carioca também faz frutificar novos processos de circulação das ideias. Novas vozes, novos meios. A imprensa se expande e toma novas formas, fazendo circular as ideias e as palavras de uma sociedade que modificava, entre outras coisas, a própria imagem que mostrava a si diante do espelho. Além do Jornal do Brasil e do Jornal do Comércio, destaca-se a fundação do Correio da Manhã, de Edmundo Bittencourt. O novo paradigma da imprensa, não vinculada mais necessariamente a grupos políticos, mas buscando sua independência no tratar dos fatos e na relação direta com a população, faz seu poder e influência aumentarem. A nova imprensa tornava-se cada vez mais o campo de disputa e frutificação intelectual da nova República, e cada vez mais não se podia passar ao largo dela aquele que tivesse pretensões na República das Letras.

O escritor e cronista Lima Barreto não perde de vista esse fato. No seu romance de estreia, intitulado Recordações do escrivão Isaías Caminha, ele traça um desenho peculiar do Rio de Janeiro a partir de seus hommes de lettres. Por isso mesmo, mais da metade do livro se passa dentro da redação do jornal $O$ Globo, falso nome que o escritor dá para se 
referir ao próprio Correio da Manhã. Utilizando-se de personagens reais sob pseudônimos nada enganadores aos leitores da época, ele caminha não só pelos acontecimentos históricos turbulentos da cidade, como apresenta figuras públicas, escritores, jornalistas, políticos, magistrados etc.

Desde suas crônicas até os romances de mais longo fôlego, sua obra se faz quase como um jogo de espelhos, a mostrar o vazio por trás das fachadas que a cidade construía para si.

O que escreve, em sua maioria, o localiza no Rio de Janeiro - no centro da cidade ou em seus subúrbios. Em especial no momento em que escreve, como salienta Margarida de Souza Neves, o Rio fazia um papel, na perspectiva geral, de "microcosmo" do Brasil, de modo que a cidade fazia papel hora de ponto de referência na direção do qual o país caminha (“O Rio civiliza-se”), ou como imagem mesmo do país como um todo (NEVES, 1991; cf. RODRIGUES, 2002). As fachadas da Avenida Central se transformam em anunciadores do ingresso do país no mundo moderno, as roupas das "donzelas botafoganas" que Lima tanto retrata em traços cínicos se transformam em figuras-símbolos de nossa proximidade com Paris. Afirma que nas transformações que se operavam nas áreas centrais da cidade havia algo de cenográfico (NEVES, 2003), um jogo que regulava e modelava aquilo que era visto, como era visto, e aquilo que se empurrava para fora do que se reinstaurava como Rio de Janeiro e, por extensão, como Brasil.

O que subjaz na relação entre a obra de Lima Barreto e este quê cenográfico das reformas urbanas levadas a cabo sob o discurso do progresso é exatamente esse confrontarse com os signos que a cidade lhe impõe. Como Tamara, cidade descrita por Marco Polo no livro Cidades Invisíveis, de Ítalo Calvino, a cidade do Rio também “diz tudo que você deve pensar, faz você repetir o discurso, e, quando você acredita estar visitando Tamara, não faz nada além de registrar os nomes com os quais ela define a si própria e todas as suas partes" (CALVINO, 1990, p. 18). Nesse confrontar-se com esses signos-bifrontes articulados pelo discurso da cidade (RAMA, 2015), os personagens barretianos - ao contrário do viajante de Calvino, cujos "olhos não veem coisas mas figuras de coisas que significam outras coisas" (CALVINO, 1990, p. 17) - assistem aos movimentos das figuras a moverem-se e a tensionarem-se nas disputas de poder, que é antes uma disputa do visível e do dizível. 
É nesse sentido, sob esse olhar que lança sobre a cidade, que a ficção de Lima Barreto irá se inserir no próprio processo de mudança artística que estava em curso. Assim como os signos da cidade, os modos como essas figuras tomavam forma e eram modeladas pela ficção se alteravam a passo de caixa. O cinematógrafo, a publicidade nos jornais, as novas fachadas da cidade: tudo contribuía para as mudanças que os personagens e os enredos sofriam como um todo na virada do século. Personagens de primeiro plano que compunham a nova imagem de uma classe alta - frequentadora do centro da cidade e dos subúrbios abastados - se entrelaçavam com um renovado interesse na cidade e suas figuras que compunham o olhar etnográfico que João do Rio lançava sobre a cidade. As antigas estruturas sociais davam lugar a uma nova relação entre raças e classes, novos meios de segregação e absorção. As novas tecnologias davam ensejo a novas formas de percepção e de construção de imagens. Tudo isso, a seu modo, fazia ruir também os modos como a hierarquia no tratamento dos temas estéticos se estabelecia. As movimentações do campo do sensível na cidade estavam diretamente relacionadas às movimentações do campo artístico. Nesse sentido, os embates que Lima Barreto trava quanto ao lugar e ao papel da sua arte face às formas clássicas entendidas como fórmula do fazer artístico se inserem também no campo de disputas do sensível que se desenhava.

Ao traçar os perfis caricaturais muitas vezes ríspidos e pouco complacentes, ele desliza seu traço satírico como que por cima de outra pintura da cidade, feita pelas próprias figuras tratadas na obra. Com isso, como que por um espelho distorcido, ele contrasta a própria ideia que estas figuras públicas haviam estabelecido de si mesmas e da cidade ao confrontar a imagem que as elites cariocas criaram de si através delas mesmas. Da mesma forma, em Numa e a Ninfa, seu foco passa a ser a classe política da cidade, apenas mencionada no primeiro livro. Tal característica da literatura à clef dos primeiros escritos de Lima fez com que muitos dos seus contemporâneos o caracterizassem como carentes de imaginação, sem uma construção de enredo original ou personagens poeticamente novos, sem ficção e, portanto - ao não obedecer as normas de representação estabelecidas como norma mimética — não propriamente artísticos (Cf. SCHWARCZ, 2017).

Como prefácio do seu livro de contos Histórias e Sonhos, publicado em 1920, ele reproduz um texto já publicado em 1916 intitulado Amplius, no qual responde a uma carta anônima recebida em razão de outro livro seu, Triste fim de Policarpo Quaresma. Nela, o 
missivista anônimo elogiava o livro, criticando, contudo, a falta de estilo do texto no que dizia respeito às normas "gregas" de composição poética, no modelo do que se entendia então como um bem escrever ideal, que tinha como referência a ideia de que as formas artísticas perfeitas teriam sido herdadas da sociedade helênica e que deveriam ser seguidas em uma obra artística que buscasse a perfeição.

Lima rapidamente repudia a ideia em dois termos. De maneira simples e concisa, ele mostra o vazio de tais formas, apenas imaginadas pelas mentes tropicais que, sentadas à beira-mar, olhavam o oceano com nostalgia de uma Europa distante, de um mundo grego que nos chega como ideia fugidia. Afirma implicar não com a Grécia em si, mas com "(...) os nossos cloróticos gregos da Barra da Corda e pançudos helenos da praia do Flamengo" (BARRETO, 2018, v.2, p. 11). É a ideia da Grécia, que segundo ele, de cinquenta em cinquenta anos tornava-se ideia nova, como um ideal instável, longe das eternas normas universais que se acreditava terem sido descobertas pelos antigos.

Bem sabe ele que, para que sua literatura possa tocar o real, à luz do que suas referências literárias entendem como o papel da arte - Flaubert, Dostoievski, Tolstoi - ela não pode estar amarrada a formas plásticas externas, que conformem as possibilidades de reprodução do real a partir de normas que nada dizem respeito aos modos de sensibilidade que a obra produz.

Mais a frente, ele mesmo afirma que "Não desejamos mais uma literatura contemplativa, o que raramente ela foi: não é mais uma literatura plástica que queremos, a encontrar beleza em deuses para sempre mortos, manequins atualmente, pois a alma que os animava já se evolou com a morte dos que os adoravam.” (BARRETO, 201, v.2, p. 13). Ele percebe que o que caracterizaria um bem representar da realidade através da ficção — do ponto de vista das formas poéticas e retóricas oficiais, pondo em hierarquia de importância temas e formas de linguagem - está diretamente ligado com a disposição política que a própria cidade conforma em seu cotidiano. A separação entre centro e subúrbio, a circulação e diferenciação dos corpos negros e brancos através das ruas que formam a teia urbana carioca, a Avenida Central, tudo isso compunha um cenário daquilo que era representável, dizível, em última instância, daquilo que estava à disposição do escritor. Negava, assim como Flaubert, a relação de necessidade entre forma e sentido, típica de um regime de arte que determinava o modo correto de representação mimética do mundo de 
acordo com aquilo que é dito - regime já há muito em vias de esgotar-se também nos trópicos. Negava também a distribuição dos papéis que a ficção tão fortemente reivindicava como estruturação do mundo - a relação de necessidade entre certos temas e estilos em relação aos atores e papéis sociais. Nesse sentido, aproximando de maneira única suas crônicas de seus contos e romances, em termos de linguagem e mesmo de temática, Lima Barreto entende que seu projeto literário não é outra coisa se não também projeto político.

Ora, não à toa Jacques Rancière identifica exatamente no realismo europeu o momento crucial de quebra com o que chama de regime poético das artes, que define a mimesis como a representação adequada do mundo, e de progressivo estabelecimento de um regime estético das artes, que define o que é artístico pelo que há de propriamente sensível na obra. Nas suas palavras: “O regime estético das artes é, antes de tudo, a ruína do sistema em que a dignidade dos temas comandava a hierarquia dos temas de representação" (Cf. RANCIÈRE, 2005). Tal passagem não é restrita ao lugar que a arte ocupa na vida comum, mas no que há de propriamente comum que se desloca de modo a ter efeitos políticos e sociais. Em Políticas da Escrita, ele explicita esse ponto afirmando que a escrita “é coisa política porque seu gesto pertence à constituição estética da comunidade e se presta, acima de tudo, a alegorizar essa constituição" (RANCIÈRE, 2017b, p. 7).

Essa constituição estética do comum é a base da ordem política, porque essa, antes de tudo, se define como "uma certa divisão das ocupações" que é da ordem da configuração do sensível: “em uma relação entre os modos do fazer, os modos do ser e os modos do dizer; entre a distribuição dos corpos, de acordo com as atribuições e finalidades, e a circulação do sentido. Entre a ordem do visível e do dizível” (RANCIÈRE, 2017b, p. 8). A isso ele denomina Partilha do Sensível.

As lutas que Lima Barreto enfrenta com sua literatura quase jornalística, cronística, podem ser entendidas como as de um alargamento do sensível no campo da arte proveniente, de um lado, das mudanças drásticas que a arte europeia - sempiterna referência da nossa sociedade tropical — passara através do romantismo e das experiências realistas, em especial na literatura com os autores franceses e russos, na aurora do regime estético (Cf. RANCIÉRE, 2013, 2017a), e de outro lado do corte traumático da virada do século XIX para o XX no Brasil, com o fim da escravidão e do Império, a emergência de novas camadas sociais e novos atores políticos. Em última instância, à reorganização desta 
trama estética do comum a que Rancière chama de Partilha do Sensível corresponde uma ficção que põe em jogo o próprio jogo do visível. Uma literatura que olha mais de perto, que dá visibilidade a lugares e pessoas sob aspectos que não eram nem representados nem representáveis, ou seja, que transformam e modificam tal partilha, esta que organiza, recorta e distribui o visível e o invisível, aquilo que pode ser experienciado e aquilo que não entra na composição do mundo enquanto experiência. Herdeiros dos movimentos artísticos da chamada geração de 1870, autores como Euclides da Cunha e Lima Barreto estão neste lugar em que as fronteiras do sensível começam a se mover (Cf. SEVCENKO, 2003).

Em outro texto posterior, o autor de Isaías Caminha, na esteira de Taine, afirma que a beleza “(...) já não está na forma, no encanto plástico, na proporção e harmonia das partes, como querem os helenizantes de última hora"; e continua: "não é um caráter extrínseco de obra, mas intrínseco, perante o qual aquele pouco vale. É a substância da obra, não são as suas aparências" (BARRETO, 2017, p. 271-272). Os helenizantes de última hora são aqueles que se apegam a um regime poético das artes que não mais pode ser sustentado, e que por isso mesmo aparecem para ele como anacrônicos, defendendo deuses mortos.

A literatura barretiana, expressão dessa mudança de sensibilidade que começava a tomar forma, percebe um aspecto intrínseco à era estética: arte é sempre muito mais que uma arte. Ela não pode ser mais entendida como uma série de formas de se organizarem imagens, sons, signos, cores, palavras. Uma arte é também a ideia do que a arte faz (RANCIÈRE, 2017b, p. 129). Nesse sentido, Rancière percebe que a música de Wagner não é só uma nova maneira de se fazer música; ela passa a ser a própria expressão do mundo não representado, ou melhor, antes da representação. Do mesmo modo, a literatura de Lima Barreto não é apenas uma nova forma de se escrever ou uma nova temática na já velha tradição do nacionalismo literário brasileiro. A sua obra é antes a ideia de que a ficção, ao mudar o ângulo em que as imagens são construídas, pode colocar a construção simbólica da sociedade face a ela mesma. É a democratização da literatura não apenas pela igualdade de tratamento dos temas, como Flaubert o inaugurou, ou pela simplificação da linguagem, egressa da experiência alargada da imprensa jornalística da época. É a democratização a partir da exposição do que há de ficcional mesmo no modo como a sociedade organiza o que é visível, no modo aristocrático em que se mostra a partilha do 
sensível, cujos mecanismos só podem ser percebidos através da ficcionalização dessa estética primeira, como um narciso a olhar sua imagem retorcida em um espelho côncavo.

É assim que, em Triste fim de Policarpo Quaresma, o heroísmo dos generais e almirantes idos à Guerra do Paraguai se mostram meras histórias mal contadas, imagens construídas de homens que nunca lutaram. Assim, Laje da Silva, em Recordações do escrivão Isaías Caminha, se mostrar admirador dos "homens dos jornais" como "sagrados, seres superiores" (BARRETO, 2018, v.1, p. 37), apesar de o personagem nunca ter lido uma única obra de Raul Gusmão, literato que ele e Isaías haviam encontrado. Tal leitura, na realidade, se torna motivo de apartamento social para Policarpo, que, conversando com o violeiro Ricardo Coração dos Outros, confessa que pensar "consola, talvez; mas faz-nos também diferentes dos outros, cava abismos entre os homens" (BARRERO, 2018, v.1., p. 259), abismo confirmado logo a frente, quando o general fala Quaresma e comenta orgulhosamente: “Aquele Quaresma podia estar bem, mas foi meter-se com livros... É isto! Eu, há bem quarenta anos, que não pego em livro...” (BARRERO, 2018, v.1., p. 295). Logo no início do livro, Lima dá o tom com que essa inadequação deve ser compreendida. O doutor Segadas, única desafeição de Quaresma, expressa sua indignação pela mania de livros deste: “Se não era formado, para que? Pedantismo!” (BARRETO, 2018, v.1, p. 207). Os livros, neste caso, seriam o privilégio e atributo do homem formado. Aqueles eram condicionados a este: o título indicava o sábio. Sem título, a leitura é mero pedantismo e perigo ao homem sério.

O caráter à clef de alguns de seus romances traz a essa questão uma outra dimensão. Além de, como Euclides da Cunha ou Balzac, dar visibilidade estética a personagens que pouco figuravam na literatura até então, inserindo-os no cerne de movimentações históricas que determinam o seu mundo e parte das suas ações; além de carregar a tragicidade do realismo social de Dostoievski, sob a perspectiva de Jean-Marie Guyau, Lima insere seus personagens no cerne de um cenário muito conhecido pela diminuta população letrada e leitora carioca: ela mesma. Nesse processo, mostra-a a partir de outro ângulo, um tanto deslocado do que ela acredita ser. Faz assim um duplo deslocar: visibiliza o antes invisível, e trans-visibiliza aquilo que já era visível. Vê em seu presente aquele escuro por entre as luzes do tempo, que Agamben define como característico do ser contemporâneo, do olhar que se lança ao seu próprio tempo numa relação de dissociação e anacronismo 
(AGAMBEN, 2009). Pode-se dizer que Lima, enquanto contemporâneo do seu tempo para seguir o que sugere Agamben - , vê o mesmo a partir do "espelho mágico e reluzente de um parodista filosófico, em cuja cabeça a época se tornou, para si mesma, consciência irônica" (NIETZSCHE, 2014, p. 121) — o extremo engajamento no presente pela dissociação que Nietzsche apresenta como fundamento de toda atitude extemporânea. Tal extemporaneidade, esse se pôr de fora do presente em que se insere, é o que Agamben identifica como ser contemporâneo.

É nesse sentido que a ficção de Lima Barreto ocupa papel central em um contexto de remodelação da estética política. A ficcionalidade própria da era estética não opera mais, como percebe Rancière, neste meio entre verdade e mentira, mas sim na indistinção entre a significação inerente do mundo e seus discursos. Em outras palavras, a soberania estética da literatura é, para Rancière, "um regime de indistinção tendencial entre a razão das ordenações descritivas e narrativas da ficção e as ordenações da descrição e interpretação dos fenômenos do mundo histórico e social" (RANCIÈRE, 2005, p. 55). Nesse sentido, a continuidade que se pode traçar entre suas crônicas, contos e romances ganha significação.

$\mathrm{O}$ processo trágico de vários personagens barretianos, associado à perda da inocência, se dá sob a forma de uma quebra da expectativa criada pelos signos autorreferentes que a capital cria e o remodelamento destes signos pela vivência do agente externo. Assim, Isaías Caminha progressivamente se decepciona com a esperada grandiosidade da capital federal, com as escolas superiores, com o mundo letrado, da mesma forma que Policarpo Quaresma vê todas as suas desesperadas tentativas de valorização do Brasil irem por terra, e Clara dos Anjos termina sua história afirmando que “nós não somos nada nessa vida” (BARRETO, 2018, v. 1, p. 868). Diferente do Julien Sorel de Stendhal, que, como comenta Rancière (2013), só encontra a verdadeira felicidade na passividade distante da prisão em que acaba a sua história, na qual o ócio é permitido àquele ao qual sempre o foi negado, os personagens barretianos nunca parecem alcançar propriamente a felicidade. Ou, quando creem encontrar, ela reside nesse frágil equilibrar-se sobre uma corda bamba, não sustentada por nada exceto o aparente vazio dessas imagens, como sabe bem o Homem que falava javanês, ao tornar-se referência intelectual de uma língua que desconhece; e o personagem de Uma Conversa, que, ao acordar na cama de uma mulher que conhecera na noite anterior, se assusta por perceber que não via mais a beleza 
que o havia seduzido, e conclui que deve ter projetado tal beleza na mulher depois de apreciar longamente estampas de grandes esculturas.

Personagens como Isaías Caminha ou como Gonzaga de Sá, no fim das contas, se veem obrigados a aceitar a inexorabilidade do jogo posto. O processo ficcional de Lima Barreto, ao levar a cabo a exposição da inadequação das imagens produzidas pela sociedade, termina por não dar saída aos personagens se não tristemente aceitar suas condições. Tais condições com que se encerra a maioria dos seus romances, que antes seriam experimentadas apenas como um conformismo mediano, tomam proporções trágicas depois que a partilha do sensível foi de tal modo chacoalhada pelo enredo no qual o leitor é levado. O comum, assim, torna-se trágico e, do mesmo modo, as ruas do Rio se movimentam.

\section{Referências}

AGAMBEN, Giorgio. “O que é o Contemporâneo?” In: O que é o Contemporâneo? E outros ensaios. Chapecó: Argos, 2009.

BARRETO, Lima. Impressões de leitura. São Paulo: Penguin Classics Companhia das Letras, 2017.

Obra Reunida (3 Volumes). Rio de Janeiro: Nova Fronteira, 2018.

CALVINO, Ítalo. As cidades invisíveis. São Paulo: Companhia das Letras, 1990.

NEVES, Margarida de Souza. Brasil, acertai vossos ponteiros. In: MUSEU DE ASTRONOMIA E AFINS. Brasil, acertai vossos ponteiros. Rio de Janeiro: MAST, 1991

"Uma capital em trompe l'oeil. O Rio de Janeiro, cidade-capital da República Velha." IN MAGALGI, Ana Maria et al. Educação no Brasil: História, cultura e política. Bragança Paulista: EDUSF, 2003, pp. 253-286.

NIETZSCHE, Friedrich. Sobre a utilidade e a desvantagem da história para a vida: segunda consideração extemporânea. São Paulo: Hedra, 2014.

RAMA, Angel. A Cidade das Letras. São Paulo: Boitempo, 2015.

RANCIÈRE, Jacques. A Partilha do Sensível: estética e política. São Paulo: EXO experimental org.; Ed. 34, 2005.

Aisthesis: Scenes from the aesthetic regime of art. London: Verso, 2013. 
O fio perdido: ensaios sobre a ficção moderna. São Paulo: Martins Fontes, 2017a.

Políticas da Escrita. São Paulo: Editora 34, 2017b.

RODRIGUES, Antônio Edmilson Martins. Em Algum Lugar do Passado. In: AZEVEDO, André Nunes de (org). Anais do Seminário Rio de Janeiro: capital e capitalidade. Rio de Janeiro: UERJ, 2002.

A Costura da Cidade. Rio de Janeiro: Bazar do Tempo, 2016.

SCHWARCZ, Lilia Moritz. Lima Barreto: triste visionário. São Paulo: Companhia das Letras, 2017.

SEVCENKO, Nicolau. Literatura como Missão: tensões sociais e criação cultural na Primeira República. São Paulo: Companhia das Letras, 2003.

SUSSEKIND, Flora. Cinematografo das Letras: literatura, técnica e modernização no Brasil. São Paulo: Companhia das Letras, 1987.

\title{
THE MIRROR PLAY OF LIMA BARRETO
}

\begin{abstract}
The realism in Lima Barreto's literature brought into discussion important questions to the artistic scene in the early 20th century. In the context of a Parnassian literature at its peak, Barretian fiction not only intended to get close to the concrete experiences of life in Brazil's capital, Rio de Janeiro, but also did so by casting over it an inverted look, caricaturing the "official" city through its other. To think about that literature with the understanding of the changes the aesthetic regime of art was putting into place, as $\mathrm{J}$. Rancière describes it, allows us to understand the way it reaches and builds the surrounding reality, and by doing that, clarifies the struggles it had to overcome to find its place as a possible sensible experience. More than just a change of artistic perspective, Barretian fiction points us to the reorganization of the distribution of the sensible (partage du sensible) within the society of Rio de Janeiro.
\end{abstract}

Keywords

Lima Barreto; Jacques Rancière; Tragedy; Distribution of the sensible; Contemporaneity 